\title{
De RH a Business Partner: relato de experiência do início da trajetória profissional
}

\author{
From HR to Business Partner: experience report from the beginning of the professional trajectory \\ De RRHH a Business Partner: informe de experiencia desde el inicio de la trayectoria profesional
}

Recebido: 17/11/2021 | Revisado: 27/11/2021 | Aceito: 01/12/2021 | Publicado: 19/12/2021

\author{
Bárbara Tavares Dias \\ ORCID: https://orcid.org/0000-0002-9665-8151 \\ Universidade Federal de Uberlândia, Brasil \\ Zup Innovation, Brasil \\ E-mail: btavaresdias@gmail.com \\ Pricila de Sousa Zarife \\ ORCID: https://orcid.org/0000-0002-0187-0425 \\ Universidade Federal de Uberlândia, Brasil \\ E-mail: profapricilazarife@gmail.com
}

\begin{abstract}
Resumo
Para se adaptarem às mudanças sociais e se manterem competitivas, as organizações foram impelidas a investir no setor de Recursos Humanos (RH). O papel de Human Resource Business Partner (HRBP) se tornou uma alternativa para as organizações que buscam maior agilidade nos processos de RH e a aproximação deste setor à estratégia de negócio da empresa. Através do relato de experiência, este trabalho visa analisar o início da trajetória profissional de uma HRBP em uma startup de tecnologia, elencando as competências desenvolvidas e as dificuldades enfrentadas. A falta de senioridade e de treinamento para ocupar a função de HRBP foram alguns dos principais fatores que dificultaram a atuação no cargo. Contudo, o acompanhamento de uma BP sênior, a realização de atividades mais direcionadas e a obtenção da confiança dos times possibilitaram uma atuação mais assertiva. Destaca-se a oportunidade de atuar e desenvolver competências essenciais como visão estratégica e sistêmica, conhecimento analítico e de negócios, comunicação e treinamento de lideranças. Devido ao destaque que o papel de HRBP vem recebendo nos últimos anos e à escassez de produções acadêmicas nacionais sobre ele, este relato busca contribuir com a trajetória de outros profissionais que visam migrar para este papel, e estimular futuras pesquisas.
\end{abstract}

Palavras-chave: Recursos humanos; RH estratégico; Business Partner; Relato de experiência.

\begin{abstract}
To adapt to social changes and remain competitive, organizations were driven to invest in the Human Resources (HR) sector. The role of Human Resource Business Partner (HRBP) has become an option for organizations searching for greater agility in HR processes and bringing this sector closer to the company's business strategy. Through the experience report, this work aims to analyze the beginning of the professional trajectory of an HRBP in a technology startup, listing the developed skills and the difficulties faced. The lack of seniority and training to fill the HRBP role were some of the main factors that made it difficult to work in this position. However, a senior BP follow-up, carrying out oriented activities, and gaining the trust of the teams allowed a more assertive performance. The opportunity to act and develop important skills such as strategic and systemic vision, analytical and business knowledge, communication, and leadership training were important to highlight. Due to the HRBP role prominent in recent years, and the lack of national academic about it, this report wants to contribute to other professionals who aim to migrate to this area and encourage future research.
\end{abstract}

Keywords: Human resources; Strategic HR; Business Partner; Experience report.

\section{Resumen}

Para adaptarse a los cambios sociales y seguir competitivas, las organizaciones se vieron impulsadas a invertir en el sector de Recursos Humanos (RRHH). El rol de Human Resource Business Partner (HRBP) se ha convertido en una alternativa para las organizaciones que buscan una mayor flexibilidad en los procesos de RRHH y acercan este sector a la estrategia de negocio de la compañía. A través del relato de experiencia, este trabajo tiene como objetivo analizar el inicio de la trayectoria profesional de un HRBP en una startup tecnológica, enumerando las habilidades desarrolladas y las dificultades enfrentadas. La falta de antigüedad y formación para ocupar el puesto de HRBP fueron algunos de los principales factores que dificultaron el trabajo en el puesto. Sin embargo, el seguimiento por parte de un BP senior, la realización de actividades más específicas y la obtención de la confianza de los equipos permitió un desempeño más asertivo. Destacamos la oportunidad para actuar y desarrollar habilidades esenciales como la visión estratégica y sistémica, el conocimiento analítico y empresarial, la comunicación y la formación en liderazgo. Debido a la importancia del rol del HRBP en los últimos años y la escasez de producciones académicas nacionales al respecto, 
este informe busca contribuir a la trayectoria de otros profesionales que pretenden migrar a este rol, y fomentar la investigación adicional.

Palabras clave: Recursos humanos; RRHH estratégico; Business Partner; Informe de experiencia.

\section{Introdução}

O setor de Recursos Humanos $(\mathrm{RH})$ passou por diferentes cenários ao decorrer da história, partindo de um caráter mais processual até obter relevância estratégica (Gemar et al., 2019). Para se adaptarem às mudanças sociais e se manterem competitivas, as organizações foram impelidas a investir no setor de RH. Por conseguinte, este acabou tendo que adotar uma atuação mais analítica e estratégica para o negócio, assumindo diferentes papéis.

Analisando a evolução histórica da área, é possível distinguir as principais diferenças de cada fase. A Administração Científica apresentou princípios norteadores para assegurar práticas gerenciais focadas no aumento da produtividade, com base na adoção de métodos científicos e defendendo a ruptura entre pensamento e execução, haja vista que o trabalhador deveria priorizar a execução de suas atividades para ganhar maior agilidade e precisão (Borges \& Yamamoto, 2014). Na Escola das Relações Humanas, o objetivo era tornar o ambiente organizacional mais humanizado, confirmando sua influência no sucesso da gestão e assumindo um novo olhar sobre o trabalhador, para além de uma "peça que atuava sobre a máquina" (Silva \& Carvalho, 2015).

$\mathrm{Na}$ Escola de Relações Industriais, o foco primordial era voltado para a fiscalização e o cumprimento de normas legais, requeridas principalmente pelos sindicatos dos trabalhadores, como condições de trabalho e benefícios (Gil, 2019). A Administração de RH pressupõe uma dinâmica mais generalista e estruturada que trabalha para que o sistema se relacione com o ambiente, entendendo as pessoas como um recurso para tal. Diante da complexidade e dinamismo do cenário atual, o termo Gestão de Pessoas (GP) foi proposto para designar uma posição estratégica na organização, com o intuito de trabalhar o alinhamento entre as metas organizacionais e os colaboradores (Monaco \& Mello, 2015), dando papel de destaque para as pessoas e suas competências neste processo.

Tradicionalmente, RH/GP é tida como uma área especialista, pautada na atuação em subsistemas (agregar, aplicar, desenvolver, recompensar, manter e monitorar pessoas) criados para atender às demandas das empresas. Seus profissionais atuam de forma especializada, com atividades de trabalho bem delimitadas e consolidadas (Molina, 2018a). Todavia, a gestão de linha, muitas vezes, não compreende como o RH/GP gera valor à organização, haja vista que o setor tende a se apresentar como mais processual, não evidenciando como seus resultados impactam as metas da organização (Barros et al., 2019).

Em meados da década de 1990, David Ulrich propôs o conceito de RH como parceiro de negócios (Human Resources Business Partner/HRBP), abrindo uma nova perspectiva de atuação (Giannakis et al., 2019). HRBP pode ser entendido como um profissional que detém conhecimentos dos subsistemas de RH, mas que estabelece uma parceria com a gestão de linha, a fim de facilitar os processos de negócio e desenvolvimento da equipe (McCracken et al., 2017), bem como mitigar problemas, contribuir e aproximar os resultados das intervenções à estratégia do negócio (Ulrich, 1997).

O principal modelo de atuação do HRBP foi proposto por Ulrich (1997), abarcando múltiplos papéis complementares divididos com base nas atividades desenvolvidas e no alvo das intervenções (Figura 1). Tais papéis suportam desde as atividades operacionais tradicionais até as de viés estratégico, possibilitando que o RH mantenha o funcionamento dos processos atuais da organização e participe de suas estratégias de desenvolvimento (Barros et al., 2019). 
Figura 1. Matriz de papéis do profissional de HRBP.

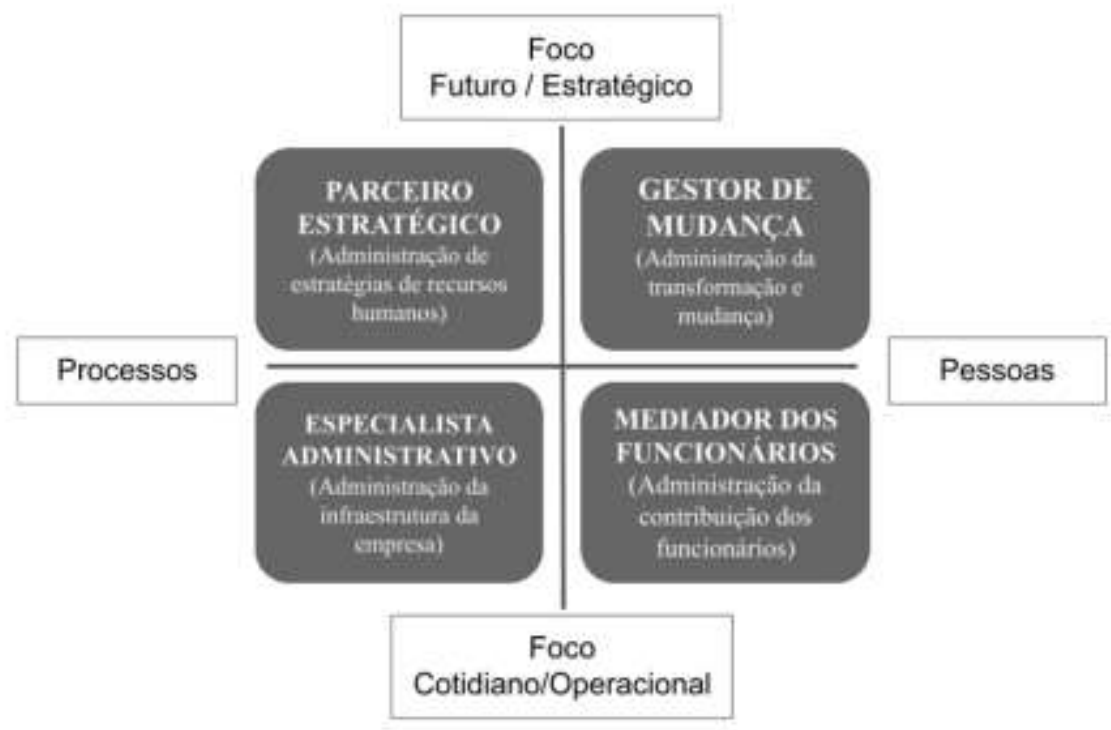

Fonte: Adaptado de Ulrich (1997, p. 24).

O papel de especialista administrativo (administração da infraestrutura da empresa) é o mais tradicional, sendo responsável pela construção e execução dos processos operacionais do setor (como recrutamento, seleção e treinamentos) e por auxiliar os gestores na condução desses processos em suas equipes (Cançado et al., 2008). O mediador dos funcionários (administração da contribuição dos funcionários) busca criar mecanismos para coletar e gerenciar as reivindicações das equipes, gerando respostas que satisfaçam os colaboradores e estejam de acordo com a estratégia da organização (Barros et al., 2019).

O gestor de mudanças (administração da transformação e da mudança) trabalha para que a organização esteja preparada para gerir e suportar transformações em seus processos e suas estruturas, atuando na identificação e condução das mudanças e buscando fomentar a flexibilidade e adaptabilidade da mesma e de seus colaboradores. O parceiro estratégico (administração de estratégias de RH) atua alinhado à alta gestão, para buscar e implantar estratégias sustentáveis de crescimento organizacional (Cançado et al., 2008). Através de diagnósticos organizacionais, ele identifica os problemas que a impedem de atingir seus objetivos, propõe, discute e fornece suporte para a execução das soluções acordadas (Barros et al., 2019).

No papel de parceiro estratégico reside a essência das atividades desempenhadas pelo profissional HRBP. Todavia, em decorrência das peculiaridades das estruturas e funções do RH nas organizações, este profissional dificilmente segue um modelo padrão na prática (Giannakis et al., 2019). Isto também se deve ao dinamismo dos relacionamentos nas organizações (McCracken et al., 2017), demandando ao HRBP o desenvolvimento de habilidades e a atuação nos quatro papéis, em maior ou menor grau (Ulrich, 1997).

O HRBP fomentou que o antigo analista de RH, antes especialista, adquirisse um olhar generalista sobre os subsistemas do setor e da organização, necessitando desenvolver seis grupos de competências principais: (1) visão de negócio; (2) domínio de ferramentas, práticas e processos de RH; (3) gestão de sistemas de informação de RH, análises e arquitetura; (4) gestão das mudanças; (5) indicadores de cultura e negócios; e (6) domínio de aspectos pessoais (D. Ulrich et al., 2015).

A primeira competência, denominada visão de negócio, envolve conhecer os elementos essenciais da empresa. Isto é, conhecer os setores internos (administrativos) e o ambiente externo (compreendendo como fatores mercadológicos afetam o negócio), considerando o trabalho da equipe/organização atendida pelo profissional de HRBP (D. Ulrich et al., 2015). 
A segunda competência essencial ao HRBP, denominada domínio de ferramentas, práticas e processos de RH, diz respeito a conhecer e ser capaz de utilizar e/ou criar ferramentas básicas pertinentes aos processos de RH/GP. Assim, este profissional precisa de habilidades para atuar em atividades de recrutamento e seleção, planejamento de carreira, treinamento e desenvolvimento, recolocação profissional, dentre outras (D. Ulrich et al., 2015).

A terceira competência, denominada gestão de sistemas de informação de RH, análises e arquitetura, envolve a capacidade de gerenciar o fluxo de informações dos colaboradores, para que os diferentes níveis da organização possam acessar as informações que lhes são pertinentes. Além disso, é preciso entender de análise de dados, de modo a auxiliar para a tomada de decisão assertiva sobre pessoas e negócios (D. Ulrich et al., 2015).

A quarta competência, denominada gestão das mudanças, diz respeito a fomentar a inovação organizacional, acompanhada da adaptabilidade e flexibilidade, de modo a tornar a organização sustentável. Além do aspecto inovador, para tal sustentabilidade organizacional, é essencial que os esforços também sejam focados na estabilidade da organização, de forma a obter o equilíbrio (D. Ulrich et al., 2015).

A quinta competência, denominada indicadores de cultura e negócios, envolve assegurar o desenvolvimento dos profissionais excepcionais, além de atuar na estratégia para a formação e manutenção de uma organização de alto padrão no mercado. Assim, este profissional deve auxiliar na instituição de uma cultura organizacional coesa voltada para que a organização seja reconhecida por indicadores de cultura e negócios relevantes no mercado (D. Ulrich et al., 2015).

A sexta competência, denominada domínio de aspectos pessoais, trata da credibilidade que o profissional de HRBP precisa transmitir. Para tanto, é preciso ter bom relacionamento interpessoal, compromisso com as entregas acordadas, uma comunicação assertiva e integridade de valores, de modo a obter o respeito dos demais líderes e pares com sua índole profissional (D. Ulrich et al., 2015).

Associado a essas competências essenciais, o profissional de HRBP precisa desenvolver um conjunto de habilidades complementares, como ter escuta ativa, resiliência e inteligência emocional (Molina, 2018b). Além disso, é preciso representar os interesses dos colaboradores, assim como definir, implementar e mensurar ações para o desenvolvimento dos mesmos e do setor de RH/GP, a fim de se aproximar da estratégia da organização (Lima \& Fischer, 2016).

O trabalho do HPBP ganhou visibilidade especial nos últimos anos. Isto se deve principalmente ao fato de as empresas reforçarem o investimento no capital humano, entendendo a importância deste para a ascensão do negócio (Gemar et al., 2019). Ele se tornou uma alternativa para as organizações que buscam mais agilidade nos processos de RH/GP, sendo que seu diferencial envolve a constante busca por inovação, capacidade de fomentar o desenvolvimento das lideranças, equipes e estruturas organizacionais, de forma ágil e qualificada (Girardi et al., 2009).

O caráter recente da difusão do HRBP, as complexas competências demandadas deste profissional e a escassez de produções acadêmicas nacionais suscitam a necessidade de entender as trajetórias profissionais de quem atua neste papel, de modo a auxiliar a formação de novos profissionais. Diante disso, este trabalho visa analisar o início da trajetória profissional de uma HRBP em uma startup de tecnologia, elencando as competências desenvolvidas e as dificuldades enfrentadas.

\section{Metodologia}

O presente trabalho se caracteriza como um relato de experiência (RE). Estes são entendidos como trabalhos de observação e intervenção original, discutidos e analisados de forma apropriada, apresentando, dentre outras possibilidades, trajetórias profissionais. REs constituem uma importante categoria da produção de conhecimentos teóricos e práticos cruciais para atuação profissional (Tosta et al., 2016).

Em consonância com o proposto por Daltro e Faria (2019), neste trabalho, uma das autoras se constitui enquanto sujeito participante do contexto da vida real em estudo, ou seja, é a profissional cuja experiência é relatada. A experiência 
apresentada neste trabalho teve iniciou em seu segundo de estágio profissionalizante, iniciado em fevereiro de 2018, atuando no setor de RH de uma startup de tecnologia e serviços, do interior de Minas Gerais. A empresa atua com consultoria em diversos segmentos, e na criação de produtos de tecnologia. A seguir, serão apresentadas, de maneira objetiva e rica, a trajetória e as técnicas empregadas pela profissional em sua atuação.

\section{Resultados e Discussão}

\subsection{Início da trajetória profissional: estagiária de RH}

A profissional ingressou na organização como estagiária no setor de $\mathrm{RH}$, sendo que suas atividades iniciais envolviam o processo de recrutamento e seleção (R\&S). Inicialmente, ela realizava divulgação de vagas, triagem de currículos e contato com candidatos. Dois meses depois, passou a realizar também entrevistas de fit cultural, agendamento e acompanhamento das entrevistas técnicas, devolutiva, proposta e admissão dos novos colaboradores.

Para conhecer cada cargo sob sua responsabilidade, a estagiária acompanhou a realização de entrevistas com especialistas de TI, a fim de mapear competências, terminologias, formação e redes sociais para busca de candidatos. Isto se justifica, pois o profissional de $R \& S$ precisa conhecer profundamente os perfis existentes no nicho em que atua e estar ciente das transformações no mundo do trabalho, o que tende a modificar seu perfil e sua própria atuação (Carvalho et al., 2016).

Este mapeamento forneceu insumos para o projeto de automatização do processo de R\&S. Nesta automatização, a estagiária participou da elaboração de um roteiro-base para contato inicial com candidatos em potencial, de acordo com o mecanismo de comunicação adotado (e-mail, Whatsapp e LinkedIn), e respostas para as perguntas mais frequentes dos candidatos. O roteiro gerou um aumento da conversão de currículos triados x candidatos contratados. A triagem se tornou mais eficiente e rápida, esclarecendo os principais questionamentos dos candidatos, que, por sua vez, aceitavam com mais frequência participar do processo seletivo.

A atuação nos processos de $R \& S$ favoreceu a obtenção conhecimento sobre o negócio da empresa e sua divisão departamental, a proximidade com os líderes de linha, o networking, o conhecimento sobre as tecnologias utilizadas pela startup, as competências demandadas dos perfis de tecnologia, além do desenvolvimento de habilidades comportamentais, como escrita, comunicação, inteligência emocional, relacionamento interpessoal e escuta ativa. A literatura indica que, próximo ao início da atuação profissional, os estudantes de Psicologia tendem a identificar a necessidade de aprimorar suas competências por meio da prática, devido à graduação fornecer conhecimentos generalistas sobre diversos domínios da Psicologia (Martins-Silva et al., 2015). Destarte, salienta-se a importância do estágio profissionalizante, ao articular teoria e prática, e fomentar a abertura de novos campos de pesquisa, aquisição de conhecimentos, ética profissional e visão crítica (Campos \& Romaro, 2017).

\subsection{Mudança na trajetória profissional: de estagiária de RH a HRBP}

Uma mudança na gestão de RH da startup culminou na reestruturação do setor, que passou a ser dividido em duas equipes: Business Partners (HRBP) e Employee Experience (EX). Tal mudança foi proposta para acompanhar a jornada do colaborador, com a EX fornecendo subsídios para a atuação da HRBP. Isto se mostra em consonância com a literatura, pois as constantes mudanças nos setores de negócios fomentam as empresas a acompanharem as tendências exigidas pelo mercado em que estão inseridas, buscando serem mais produtivas, tecnológicas e evoluídas em suas estruturas e processos de trabalho (Molina, 2018a).

A equipe de EX era responsável pela experiência dos colaboradores, realizando atividades como pesquisas gerais de satisfação, eventos internos e marketing institucional. O time de HRBP, passou a ser composto por três duplas, formadas por uma analista sênior e uma estagiária, responsáveis pelo apoio e desenvolvimento das equipes. À estagiária era incumbida a 
realização de processos operacionais, como $R \& S$, pesquisas de satisfação internas das equipes e controle de dados dos colaboradores. Além disso, ela auxiliava a HRBP nos processos de desenvolvimento das equipes, participava de reuniões com as lideranças, acompanhava indicadores de negócio e auxiliava no fortalecimento de laços com os clientes externos. Esta realidade de atuação, inicialmente operacional, é relativamente comum na área organizacional. Tradicionalmente, os estágios na área de Psicologia Organizacional e do Trabalho são direcionados a atividades clássicas de R\&S, o que, muitas vezes, faz com que a área fique carente de profissionais com capacidade de atuação estratégica (Campos, 2009).

Atuar com a HRBP possibilitou à estagiária ter contato com os outros subsistemas de RH, como desenvolvimento de equipes e de liderança, pesquisa de clima e de satisfação e avaliação de desempenho. Com essa experiência, especialmente ligada à visão de negócio e identificação do perfil profissional esperado pela organização, a estagiária pôde contribuir ativamente com os processos antes de responsabilidade apenas da HRBP, como o desenvolvimento da equipe. Isto porque, em sua atuação, o recrutador deve considerar cada candidato como possível futuro líder, fortalecendo a contratação de profissionais que se encaixem na cultura organizacional e abarcando a visão de futuro naquela empresa. $\mathrm{O} \& \& S$ assertivo deve focar não apenas nas competências do cargo, mas também na adesão aos aspectos da cultura organizacional (Estevam \& Molteni, 2018).

A fim de mensurar sua evolução e quais pontos precisava desenvolver para ser efetivada na empresa, com cinco meses de atuação, a estagiária solicitou uma avaliação de seu desempenho no estágio. A avaliação demonstrou que ela atendia os requisitos básicos de uma Analista Júnior de nível 1, devido a capacidade de conduzir processos de baixa e média complexidade com autonomia, culminando em sua efetivação na startup.

\subsection{Atividades desempenhadas como HRBP}

Gradualmente, a agora profissional foi atribuída às responsabilidades individuais dos processos junto aos times, com o suporte da HRBP com maior experiência, através de mentoria e feedbacks. Para o acompanhamento das atividades, eram realizadas reuniões semanais, nas quais ela apresentava as atividades realizadas na semana anterior, as que realizaria na semana seguinte e os pontos em que precisaria de suporte da HRBP mais experiente.

Inicialmente, a profissional atendia quatro times, totalizando 130 colaboradores. O desafio enfrentado neste período envolvia estabelecer vínculo com as equipes, entender o negócio de cada uma delas, criar ações para evolução do colaborador e da liderança e dar suporte operacional. De acordo com a literatura, a confiança entre cliente interno e HRBP é essencial para o sucesso do processo, podendo ser conquistada através de trabalho em equipe, ética e constância nos resultados (Molina, 2018b).

Na implementação de um processo de HRBP, precisam ser consideradas quatro etapas: acordo, diagnóstico, projeto, e execução e controle, todas seguidas pela profissional para estabelecimento de vínculos. A primeira etapa (acordo) envolve alinhar as expectativas e esclarecer as responsabilidades de cada integrante do time (Molina, 2018b). Nesta etapa, a profissional conduziu conversas com as lideranças de cada time, buscando levantar o entendimento dos líderes sobre o papel de HRBP, as expectativas sobre a atuação dela, as insatisfações do time e o conhecimento do negócio, além de definir os próximos passos.

A segunda etapa (diagnóstico) envolve coletar e analisar dados para identificar o problema a ser resolvido (Molina, 2018b). Para tanto, a profissional conduziu uma pesquisa de mapeamento da percepção do time e da liderança intermediária sobre a satisfação com o time, com a liderança e expectativas de carreira, por meio de entrevistas individuais. Isso possibilitou entender as relações entre as pessoas do time, entre o time e a liderança, o perfil da equipe e gerar vínculo inicial com cada colaborador. 
A terceira etapa (projeto) envolve o planejamento das ações para solucionar o problema, definindo os responsáveis por cada etapa e os prazos (Molina, 2018b). Neste ponto, a profissional apresentou os resultados da pesquisa para as lideranças, demonstrando o mapeamento da perspectiva dos times e as intervenções necessárias para solucionar os problemas. Isto colaborou para o fortalecimento da confiança dos líderes na HRBP e para o fortalecimento de vínculos com a equipe, ao propor ações de melhorias rápidas e assertivas, em pouco tempo de atuação.

A última etapa (execução e controle) envolve executar as ações acordadas e medir sua eficácia (Molina, 2018b). Das intervenções realizadas, três tiveram maior impacto: (1) aproximação dos diretores com as equipes, com visitas quinzenais à matriz, para a apresentação dos avanços daquela estrutura na parte de negócios; (2) aplicação mensal de pesquisa de satisfação com time, liderança e projeto; (3) reuniões semanais com os líderes para coletar pontos de melhoria, informar status de indicadores (como pesquisas de satisfação, vagas e demandas da semana anterior) e estruturar prioridades nas atividades semanais.

No início de sua atuação, a profissional realizava atividades por demanda até obter a confiança da liderança sobre suas entregas e adquirir mais abertura para influenciar os líderes. Esta atuação inicial se assemelha ao modelo de consultoria de compra de serviços. Nele, o cliente interno faz o levantamento dos pontos de intervenção e o HRBP planeja e executa ações para sanar os problemas. Este modelo é estabelecido quando ainda não existe um elo de confiança entre o líder e o HRBP, o papel de HRBP não está consolidado na organização ou essa posição é ocupada por um profissional júnior (Molina, 2018b).

O entendimento do negócio é um ponto fulcral para a atuação em HRBP, configurando-se como uma competência essencial (D. Ulrich et al., 2015). Ciente disso, a profissional participou, como ouvinte, de reuniões técnicas e de definições de negócio, traçando um paralelo entre o que seria sucesso para o cliente e as ações estabelecidas para o desenvolvimento da equipe. Isto garantiu bastante sinergia nas ações de pessoas e negócio, tornando-as mais assertivas e estratégicas.

Em uma nova reestruturação do RH, a área passou a atender de forma descentralizada, com as HRBPs incluídas no desenho de estrutura dos times de TI. Neste movimento, os gestores de linha passaram a compartilhar com a HRBP as responsabilidades pelos processos de R\&S, sendo eles os responsáveis por realizar as etapas de triagem, contato, entrevista e seleção de pessoal. O apoio da HRBP seria mantido apenas em casos de exceção, como dúvida na avaliação, contratação de cargos estratégicos ou grande volume de vagas. A literatura indica que, para o sucesso da parceria entre HRBP e gestores, é imprescindível que o primeiro compartilhe os conhecimentos que tem sobre os processos de RH, e que o gestor assuma a responsabilidade pela gestão dos colaboradores de sua estrutura (Lima \& Zuppani, 2016).

A mudança gerou ganhos pela aproximação da HRBP com as rotinas dos times que ela atendia, com destaque para maior autonomia e visão de negócio, HRBP passou a ser vista como estratégica, fortalecimento do vínculo com time e liderança, e mais agilidade na criação de fluxos e processos. Entretanto, também foram constatados pontos prejudiciais, como a descentralização da informação que prejudicou a troca de aprendizados entre as HRBPs (especialmente a base de formação das iniciantes), a priorização de fluxos de pessoas (definida exclusivamente pela liderança técnica) e dificuldades na avaliação de fit cultural (ocorrendo com mais falhas).

Após uma análise de competência e disponibilidade, com seis meses no cargo, foi oferecido à profissional a oportunidade de ser a HRBP responsável de uma filial, a qual havia passado por uma significativa expansão em poucos meses. Segundo a HRBP líder da profissional, os pontos de destaque que embasaram essa oferta foram o domínio dos processos de R\&S, os conhecimentos sobre a cultura da empresa, os feedbacks positivos coletados com as lideranças atendidas pela profissional, a capacidade de associar o crescimento do negócio com o crescimento do time e a disponibilidade previamente averiguada para mudanças de cidade.

$\mathrm{Na}$ filial, o desafio da HRBP era apoiar na expansão do time (contratação) e atuar na disseminação de cultura, criação e implementação de fluxos para o desenvolvimento da equipe e coaching para o desenvolvimento das lideranças. Em um 
primeiro momento, havia a necessidade de atuação como HRBP, mas também como generalista de GP/RH, em decorrência do caráter recente da filial. Desta forma, a profissional foi responsável pelos processos do departamento pessoal, controle financeiro, facilities (manutenção física do ambiente de trabalho), compras e R\&S. Tal atuação está de acordo com a literatura, ao passo que o HRBP deve considerar as necessidades do ambiente ao propor e executar ações nos processos de RH (Molina, 2018a).

Com as demandas iniciais supridas, a profissional realizou levantamento de indicadores para a criação de ações, de modo a atuar na retenção dos colaboradores. Os indicadores foram empregados para embasar mudanças assertivas. Por exemplo, a partir do levantamento feito pela profissional sobre a quantidade de vagas $\mathrm{x}$ tempo necessário de dedicação para o fechamento delas, bem como o cruzamento destes dados com todos os processos que a HRBP era responsável por conduzir, foi obtida a autorização para a contratação de uma especialista focada em R\&S. Isto permitiu à HRBP focar seus esforços em outros processos.

Outro exemplo de mudança gerada a partir de indicadores foi a mudança do espaço físico da filial. Durante três meses, a profissional analisou (1) pesquisa de satisfação que indicou baixa avaliação na estrutura de trabalho; (2) dados do Net Promoter Score (NPS) da sede e das filiais indicando que uma boa estrutura física pode ser uma vantagem no R\&S; e (3) projeção de expansão do quadro de colaboradores, incompatível com a estrutura vigente. Com base nestas informações, ela conseguiu antecipar, em seis meses, a mudança de espaço físico da filial. Tal alteração melhorou consideravelmente os indicadores supracitados, indicando a assertividade da ação proposta.

Atuando em todos esses processos e setores, a profissional desenvolveu o conhecimento sobre novas funções e setores, fortalecendo a visão generalista requerida de uma HRBP. Mais uma vez, o apoio no processo de R\&S do time forneceu conhecimento amplo sobre o negócio atendido e maior abertura com a equipe e com a liderança, podendo se aprofundar nas necessidades do time e do negócio.

Na atuação como HRBP, a profissional também desenvolveu o aprendizado sobre entrega de valor para o cliente interno. Ao conseguir atuar em outros departamentos, suprindo necessidades imediatas dos colaboradores e atuando para que elas não voltassem a acontecer, conseguiu gerar mais valor em seu trabalho do que se estivesse se limitado ao escopo de RH. A literatura aponta que saber se adaptar ao cenário e entender as reais necessidades do negócio é um ponto crucial na atuação deste profissional. Por ter uma posição de agente de transformação, de forma abrangente ou mínima, o HRBP precisa estar pronto para fornecer suporte para o momento da organização (Molina, 2018b).

Todavia, pela distância geográfica, foi escassa a troca de informações com outras HRBPs sobre processos de melhoria de outras equipes. Ainda, por ser a única HRBP da filial e ter pouca experiência, a profissional obteve pouco suporte para evolução neste papel, sendo necessários meses para o estabelecimento dos processos básicos que poderiam ter sido implementados com maior agilidade com as orientações necessárias. Ocorre que, devido a necessidade de que o HRBP tenha conhecimento para transitar e influenciar os diversos subsistemas da organização, é especialmente requerida senioridade deste profissional (Molina, 2018a), o que não ocorreu neste caso.

Devido a dificuldades pessoais e profissionais enfrentadas durante a estadia na filial, a profissional optou por retornar para a cidade de origem, após nove meses. Com sua volta à matriz, ela assumiu a posição de HRBP de três times: Produtos, Infraestrutura e Segurança, e Staff. Alguns times ainda não possuíam uma estrutura definida, nem realizavam os processos básicos de gestão. Então, num primeiro momento, a profissional atuou novamente nos processos de R\&S, até gerar indicadores que justificassem a alocação de uma recrutadora nesses times, conforme a experiência anterior. Do mesmo modo, trabalhou na estruturação dos times, estabelecendo camadas de liderança e separação dos projetos, atuou fortemente no processo de aculturamento de novas lideranças e auxiliou as lideranças no estabelecimento de novas áreas dentro da startup (como o time 
de Segurança). Desta vez, vale destacar que com uma experiência um pouco maior, ela conseguiu pleitear que as mudanças ocorressem com maior rapidez.

Atualmente, a profissional está há três anos no papel de HRBP, ocupando o nível pleno e sendo responsável pelo atendimento de duas estruturas no centro de negócios de produtos da startup. Na organização em que atua, ocupar o nível pleno de HRBP implica ter capacidade de atuar em novos nichos, como a formação e o planejamento de sucessão de liderança, bem como a construção de processos e/ou ferramentas que possam ser utilizados(a) por HRBPs de outros centros de negócios.

Em sua atuação, a profissional frequentemente utiliza plataformas para análises de dados em massa, sendo requisitada profundidade na explicação dos resultados das análises, clareza na elaboração dos prognósticos e acompanhamento na tratativa das ações estabelecidas, atuando também de forma preventiva sobre os indicadores. Ciente de que indicadores são essenciais para respaldar tomadas de decisões nas organizações, é importante estabelecer parâmetros para a produção deles e facilitar o acesso a tais informações por todos os setores necessários (Fernandes, 2004). A facilidade de acesso também auxilia na visibilidade do setor de RH ao constituir um dispositivo para informar aos clientes internos e externos sobre os impactos das ações e processos do setor no desempenho do negócio (Cesar, 2015).

Em sua atuação, é esperado que a profissional tenha autonomia na definição e priorização das entregas, solicitando o acompanhamento da liderança apenas em casos de exceção, sendo capaz de liderar múltiplos projetos sem deixar de entregar as demandas principais. Assim, o nível de influência e capacidade de escalonamento é desejado cada vez mais dessa profissional, além do acompanhamento do mercado sobre tendências do papel de HRBP e sobre o nicho de negócio do time que atende.

Conforme a literatura, o HRBP pode ter seu escopo de atuação variado dependendo da maturidade da organização, a forma como ela entende o trabalho da área de RH e a respectiva senioridade do HRBP (Molina, 2018b). Com a experiência obtida, a profissional adquiriu mais conhecimento para conduzir os processos, conseguindo orientar outros profissionais. Hoje, a ela é a segunda HRBP com mais tempo de empresa, sendo frequentemente requisitada para propagar sua experiência e a cultura organizacional para as novas gerações de HRBPs da startup.

\subsection{Dificuldades encontradas $X$ competências desenvolvidas como HRBP}

Dentre as dificuldades do processo de se tornar HRBP, a falta de experiência fez com que a profissional cometesse erros que poderiam ser evitados com mais conhecimento sobre as teorias e práticas que envolvem o $\mathrm{RH}$, ou um treinamento e acompanhamento adequado para uma HRBP em formação. Novamente, destaca-se a importância da senioridade para atuação como tenha HRBP, de modo a obter o conhecimento e influência na organização (Molina, 2018a). No caso relatado, os conhecimentos obtidos na graduação serviram de grande apoio nesse início, mas o suporte de uma HRBP mais experiente fornecia o direcionamento mais personalizado acerca de qual conhecimento deveria ser aplicado em determinado contexto, minimizando alguns problemas enfrentados.

A falta de um treinamento avançado para assumir esta função, e os momentos em que houve a falta de um acompanhamento implicaram na ocorrência de alguns equívocos em sua atuação (especialmente de tempo de realização das atividades) ou na falta de uma postura mais assertiva em certos momentos. Tais situações provocaram na profissional alguns momentos de angústia, em que ela se questionava sobre suas decisões.

Outra dificuldade identificada em sua trajetória foi a atuação baseada em indicadores e a profundidade do negócio, haja vista que esses aspectos não haviam sido explorados com tanta eloquência em sua formação. Assim, a profissional não sentia ter uma base prática consolidada para atuar com um olhar apurado para essas vertentes. De acordo com D. Ulrich et al. (2015), entender indicadores de cultura e negócios constitui uma das competências essenciais aos profissionais de HRBP, sendo a falta de domínio um problema em potencial. Entretanto, a profissional constatou a importância de aprofundar seus conhecimentos sobre o uso de indicadores para embasar análises e propostas de ações, buscando formação específica para tal. 
Por outro lado, iniciar a atuação profissional realizando processos de R\&S possibilitou à profissional entender com mais profundidade os requisitos técnicos, tanto dos perfis da equipe, quanto de negócios. Este se mostrou um caminho assertivo para que ela estabelecesse uma relação de confiança com a equipe e com a liderança, através de entregas rápidas, de baixa complexidade e alto valor agregado. Isto porque $R \& S$ são uns dos primeiros e mais importantes segmentos da área de RH/GP, tornando-se uma ferramenta crucial para o alcance das estratégias nos segmentos de inovação, competitividade, crescimento no mercado e em negócio (Cassiano et al., 2016).

A profissional compreendeu que o papel de HRBP não precisa ou deve ser estático/especializado. Como apontado na literatura, o HRBP deve considerar as características e necessidades do ambiente, para propor soluções que impactem o negócio (Molina, 2018a). Ou seja, o maior objetivo é conseguir planejar e executar ações assertivas dentro dos times, de modo a auxiliar no alcance das metas organizacionais. Por exemplo, se o maior problema constatado estiver nos processos de departamento pessoal, é neste setor que o HRBP deve atuar para gerar valor ao seu cliente. Para isso, é preciso atenção aos indicadores coletados no time, e atuar preventivamente em ações diversas.

Normalmente, o papel de HRBP no mercado demanda profissionais com níveis de senioridade elevados (Molina, 2018a). Ter a oportunidade de atuar neste papel, mesmo que ainda com pouca experiência, trouxe desde o começo da trajetória profissional a importância da visão do todo, alinhando gestão de pessoas com negócios. Essa visão sistêmica ofereceu maior espaço de debate para a profissional no alinhamento estratégico da organização, permitindo um campo abrangente de atuação, para além dos papéis tradicionais de RH/GP.

Por fim, reforça-se que a atuação como parceiro estratégico toma como base a prática de novas atividades no escopo do profissional de RH/GP, buscando o foco em atividades com maior impacto na estratégia organizacional (Botter, Rosa, \& Lima, 2018). Diante disso, a trajetória possibilitou à profissional uma atuação plural, visando um maior espaço de fala nas decisões de negócio, domínio sobre práticas generalistas de RH/GP e conhecimento do mercado em que atuava

\section{Considerações Finais}

Este trabalho buscou analisar o início da trajetória profissional de uma HRBP em uma startup de tecnologia, elencando as competências desenvolvidas e as dificuldades enfrentadas. Nele, foram apresentados desde os processos realizados em sua atuação inicial como estagiária de RH/GP até sua consolidação enquanto profissional de HRBP.

Observa-se que a pouca experiência e conhecimento teórico inicial acerca da atuação de HRBP influenciaram sua interpretação dos cenários e dos indicadores, sendo algumas vezes tratados de maneira superficial. Além disso, durante a transição de uma atuação tradicional de RH para o papel de HRBP, foi necessária uma quebra de paradigmas vinculados ao olhar especializado de RH (restrito aos processos desenvolvidos por esse setor), de modo a ampliar o olhar para o negócio e outras áreas que cruzavam com a experiência do colaborador. Deste modo, foi possível adotar um olhar flexível e estratégico, essencial para atuar como HRBP.

Atuando desde o início da implementação desse papel na startup, a profissional desenvolveu competências ainda pouco disponíveis no mercado, como comunicação, visão estratégica e sistêmica, conhecimento analítico e de negócios, e desenvolvimento de lideranças. Através da experiência relatada neste trabalho, pode-se compreender as etapas que mais contribuíram ou dificultaram a atuação como HRBP. Conforme apontado na literatura, é desejável que o profissional possua senioridade para atuar neste papel (Molina, 2018b), mas, em casos de migração ou início de carreira, como aqui relatado, este trabalho deixa explícita a importância de buscar mentoria de HRBPs mais experientes e treinamentos para atuação assertiva.

Nota-se a escassez de produções acadêmicas nacionais referentes ao papel do HRBP dentro das organizações. O aumento da publicação de artigos sobre tal tema agregaria as organizações devido às mudanças enfrentadas por elas na contemporaneidade, e sobre quais papéis são necessários para fornecer suporte adequada a tais mudanças. Assim, sugere-se a 
realização de pesquisas futuras que tracem o perfil dos profissionais de HRBP brasileiros, bem como mapeiem suas estratégias de atuação, de modo a auxiliar na formação de novos profissionais.

\section{Referências}

Barros, F. M. R., Penha, P. X., Silva, C. M. D., Silva, A. K., \& Gomes, A. F. L. de P. (2019). Os múltiplos papéis do RH em empresas da microrregião do Alto Paraopeba/MG. Revista de Carreiras \& Pessoas (ReCaPe), 9(2), 250-265. https://doi.org/10.20503/recape.v9i2.38894

Borges, L. O. \& Yamamoto, O. H., (2014). Mundo do trabalho: Histórica e desafios contemporâneos. In J. C. Zanelli, J. E. Borges-Andrade, \& A. V. B. Bastos (Orgs.), Psicologia, organizações e trabalho no Brasil (2a ed.), 25-72. Artmed.

Botter, J., Rosa, D. G., \& Lima, L. C. (2018). As diferenças entre o modelo e as competências da parceria estratégica entre a gestão de recursos humanos e os gestores de linha em empresas nacionais e multinacionais. Internext, 13(3), 28-41. https://doi.org/10.18568/1980-4865.13328-41

Campos, D. C. (2009). Atuação de estagiários em psicologia do trabalho com grupos. Revista da SPAGESP, 10(1), 53-59. http://pepsic.bvsalud.org/pdf/rspagesp/v10n1/v10n1a09.pdf

Campos, D. C., \& Romaro, R. A. (2017). Os estágios em psicologia organizacional e psicologia do trabalho tal como acontecem: Com a palavra a coordenação de estágio. In D. C. Campos (Org.), Atuando em psicologia do trabalho, psicologia organizacional e recursos humanos (2a ed.), 10-14. LTC.

Cançado, V. L., Medeiros, N. L. D., \& Jeunon, E. E. (2008). O profissional da informação: Uma análise baseada no modelo de múltiplos papéis de Ulrich. Perspectivas em Ciência da Informação, 13(2), 196-218. https://doi.org/10.1590/S1413-99362008000200013

Carvalho, I. M. V., Passos, A. E. V. M., \& Saraiva, S. B. C. (2016). Recrutamento e seleção por competência (2a ed.). Editora FGV.

Cassiano, C. N., Lima, L. C., \& Zuppani, T. dos S. (2016). A eficiência das redes sociais em processos de recrutamento organizacional. NAVUS - Revista de Gestão e Tecnologia, 6(2), 52-67. https://doi.org/10.22279/navus.2016.v6n2.p52-67.362

Cesar, A. M. R. V. (2015). Medidas de desempenho da área de recursos humanos e seu relacionamento com indicadores de desempenho econômico. REGERevista de Gestão, 22(1), 97-114. https://doi.org/10.5700/rege553

Daltro, M. R., \& Faria, A. A. (2019). Relato de experiência: Uma narrativa científica na pós-modernidade. Estudos e Pesquisas em Psicologia, $19(1), 223-237$. http://pepsic.bvsalud.org/pdf/epp/v19n1/v19n1a13.pdf

Estevam, C. O., \& Molteni, A. (2018). Recrutamento e seleção: Visão estratégica para o sucesso organizacional. Revista Terceiro Setor \& Gestão, 12(1), 3448. http://dx.doi.org/10.33947/1982-3290-v12n1-3649

Fernandes, D. R. (2004). Uma contribuição sobre a construção de indicadores e sua importância para a gestão empresarial. Revista da FAE, 7(1), 1-18. Recuperado de https://revistafae.fae.edu/revistafae/article/view/430

Gemar, G., Negrón-González, A. M., Lozano-Piedrahita, C. J., Guzmán-Parra, V. F., \& Rosado, N. (2019). Procedure for the continuous improvement of human resource management. Ingeniería e Investigación, 39(1), 53-62. https://doi.org/10.15446/ing.investig.v39n1.72402

Giannakis, D., Chalikias, I., \& Tsirigoti, E. (2019). The effect of sales and HRM strategic alignment on a corporate sustainable competitive advantage: The significant role of the HR business partner. International Journal of Innovation, Management and Technology, 10(6), 207-218. https://doi.org/10.18178/ijimt.2019.10.6.863

Gil, A. C. (2019). Gestão de pessoas: Enfoque nos papéis estratégicos (2a ed.). Atlas.

Girardi, D. M., Lapolli, E. M., \& Tosta, K. C. B. T. (2009). A consultoria interna de recursos humanos como prática catalisadora da gestão do conhecimento organizacional. Ciências da Administração, 11(25), 151-176. https://dialnet.unirioja.es/servlet/articulo?codigo=3710793

Lima, L. C. \& Zuppani, T. (2016). Evidências da parceria estratégica entre a gestão de recursos humanos e os gestores de Linha. In Anais XIX SemeAd. Seminários de Administração (pp. 1-17). São Paulo, Brasil. https://login.semead.com.br/19semead/anais/resumo.php?cod_trabalho=145

Martins-Silva, P. O., Silva Junior, A., \& Libardi, M. B. A. O. (2015). Psicologia organizacional e do trabalho: Relato de experiência em estágio supervisionado. Psicologia Ciência e Profissão, 35(4), 1327-1339. https://doi.org/10.1590/1982-3703000722014

McCracken, M., O'Kane, P., Brown, T. C., \& McCrory, M. (2017). Human resource business partner lifecycle model: Exploring how the relationship between HRBPs and their line manager partners evolves. Human Resource Management Journal, 27(1), 58-74. https://doi.org/10.1111/1748-8583.12125

Molina, F. M. C. (2018a). Entendendo o negócio: O consultor interno de recursos humanos (CIRH) e contexto atual. In J. Camilo, J. L. S. Penhalbel, \& L. M. Castelhano (Orgs.), Gestão de pessoas: Consultoria interna de recursos humanos (pp. 11-28). Editora Senac São Paulo.

Molina, F. M. C. (2018b). O papel do consultor interno. In J. Camilo, J. L. S. Penhalbel, \& L. M. Castelhano (Orgs.), Gestão de pessoas: Consultoria interna de recursos humanos (pp. 29-42). São Paulo, SP: Editora Senac São Paulo.

Monaco, F. de F., \& Mello, A. F. M. de (2015). A Administração de recursos humanos e a implantação da gestão da qualidade: Um enfoque na resistência à mudança. RACE - Revista de Administração, Contabilidade e Economia, 5(1), 35-48. https://portalperiodicos.unoesc.edu.br/race/article/view/8736

Silva, F. S. da, \& Carvalho, E. A. de (2015). Recursos humanos: Do operacional ao estratégico. Revista Uningá Review, 24(1), 124-131. http://revista.uninga.br/index.php/uningareviews/article/view/1663 
Research, Society and Development, v. 10, n. 16, e284101623422, 2021

(CC BY 4.0) | ISSN 2525-3409 | DOI: http://dx.doi.org/10.33448/rsd-v10i16.23422

Tosta, L., Silva, T., \& Scorsolini-Comin, F. (2016). O relato de experiência profissional e sua veiculação na ciência psicológica. Clínica \& Cultura, 2(1), 6273. https://seer.ufs.br/index.php/clinicaecultura/article/view/6016

Ulrich, D. (1997). Human Resource Champions: The next agenda for adding value and delivering results. Harvard Business School Press.

Ulrich, D., Brockbank, W., Ulrich, M., \& Kryscynski, D. (2015). Toward a synthesis of HR competency models: The common HR "food groups". People and Strategy, 38(4), 56-65. http://hdl.lib.byu.edu/1877/3938 